\title{
Nuclear liability for international transport accidents under the modernised nuclear liability conventions: an assessment
}

\author{
Nathalie L.J.T. Horbach \\ Nuclear Law Programme, Centre for Energy, \\ Petroleum and Mineral Law and Policy, University of Dundee, \\ Dundee DD1 4HN, UK \\ E-mail: n.horbach@dundee.ac.uk \\ and \\ Independent Nuclear and Environmental Law Consultant, \\ Hobbemastraat 6-II, 1071 ZA Amsterdam, The Netherlands \\ E-mail: nathalieljt@freesurf.fr
}

\begin{abstract}
The last decade saw the adoption of four new nuclear liability treaties, resulting in a modernisation of the existing nuclear liability regime. If applicable, the nuclear liability situation, in the case of international transport, might become more complicated, but at the same time also more transparent, should these treaties enter into force for certain States, but not for others. For instance, the extension of the geographical scope and the definition of nuclear damage, as well as the increased liability amounts, will result in higher liability coverage for a wider category of victims than before. On the other hand, the risks of claims outside the nuclear liability regime under other laws and/or in different courts, might be reduced. This paper analyses the possible consequences of nuclear liability protection applicable to multimodal nuclear transport, the cause génératrice being a catastrophic accident causing wide-scale transboundary damage involving different countries.
\end{abstract}

Keywords: allocation of liability; applicable law; EEZ; exoneration; jurisdiction; liability limits; nuclear damage; reciprocity; State funds; transport accident; transport routes.

Reference to this paper should be made as follows:. Horbach, N.L.J.T. (2006) 'Nuclear liability for international transport accidents under the modernised nuclear liability conventions: an assessment', Int. J. Nuclear Law, Vol. 1, No. 2, pp.189-198.

Biographical notes: Natalie Horbach holds a $\mathrm{PhD}$ from Leiden University in International Law on State Responsibility and Civil Liability for Transboundary Damage, and is responsible for many publications in the area of nuclear energy and environmental liability law. In addition, she is Director of the Nuclear Law Programme, Centre for Energy, Petroleum and Mineral Law and Policy, University of Dundee, Scotland. 


\section{Introduction}

The nuclear activities in which nuclear operators are involved pose a number of liability risks which are normally well-insured and are regulated by the 1960 Paris Convention (PC), the 1963 Brussels Supplementary Convention (BSC), the 1963 Vienna Convention (VC), the 1988 Joint Protocol linking the Paris and Vienna Conventions (Joint Protocol), the 1971 Convention Relating to Civil Liability in the Field of Maritime Carriage of Nuclear Material (1971 Maritime Convention), in addition to domestic nuclear liability legislation, implementing the respective treaty provisions.

Apart from the operation of nuclear power plants per se, a special liability risk is posed by transfrontier shipments of nuclear materials from nuclear facilities to and from other nuclear facilities in and through various countries. Such liability risk is especially real and multifaceted, if the receiving, sending or transit States are not part of any international nuclear liability treaty regime, or have joined a different nuclear liability regime.

The latter situation, is, in fact, more likely to arise with the adoption of the four modernised nuclear liability treaties, i.e. the 1997 VC, the two Protocols of 2004 revising the Paris Convention and Brussels Supplementary Convention (2004 PC and 2004 BSC), and the 1997 CSC. These treaties tend to add to the ambiguity of the liability risks involved in transport activities, especially until such time as all the Contracting Parties of the original version of the treaties have ratified the modernised ones. Moreover, it should be emphasised, particularly in respect of liability associated with nuclear transport, that States with a majority of the world's operating nuclear power plants are not yet parties to any nuclear liability treaty. Shipments between and among them thus are not covered by any treaty.

It is, therefore, unfortunate that with all existing nuclear liability treaties in place, the number of which is unique within international law to cover one and the same topic, they lack a comprehensive and unified international legal regime for nuclear accidents under which potential nuclear damage claims can be settled in a predictable and transparent manner. In fact, this labyrinth of international agreements on nuclear liability, the interrelations of which have become increasingly complicated, is especially problematic in respect of nuclear transport accidents which could easily result in the application of more than one (nuclear) liability agreement. This is further multiplied in case of multimodal transnational shipments that habitually involve a number of countries, apart from the sending and receiving countries, i.e. transit countries in respect of transport by land or waterways, and coastal States in respect of transport by sea.

Finally, as highlighted by the 11 September 2001 attacks in New York and Washington DC, the train attacks in Madrid of 11 March 2004, and the subway attacks in London of June 2005, a new and very real risk involved in case of nuclear shipments is terrorism, i.e. a terrorist attack on any of the means of transport and resulting liability questions involved.

\section{Liability for nuclear transport accidents}

\subsection{Transnational multimodal transport: issues involved}

Within the national boundaries of States that have adopted comprehensive nuclear liability laws and even between States that are parties to one of the international nuclear liability conventions, nuclear liability transport regimes are usually relatively well-defined. 
However, once a shipment crosses international boundaries, potential nuclear liability presents a number of intricate and largely untested legal issues. This is particularly the case for shipments while on the high seas. Many elements can bear on liability for nuclear damage during transport. For example, liability may depend upon the origin or destination of the shipment; the type of nuclear material involved; the situs of the transport accident (applicable geographical scope, e.g. EEZ); the nature of nuclear damage involved (e.g. environmental cleanup or retrieval at sea, pure ecological damage); the nationality and domiciles of the victims (e.g. Austrians); allocation of jurisdiction or applicable law. Depending upon these and other circumstances, the law applied could be the law of the forum, the law of the place where the accident or damages occurred, or the law of the place with the most significant links with the parties. Moreover, the availability and degree of insurance coverage and/or State funds further determines the degree of successful compensation for damages, if liability is established.

Under the general international rules on nuclear liability, as incorporated by the nuclear liability treaties, three main principles are to be separated that influence the decision on which law and the extent of liability is applicable to a transport incident. These relate to the person liable, the court having jurisdiction and the national (implementing) law applicable.

\subsection{Allocation of liability for transport accidents}

The nuclear liability treaties contain rules to determine the allocation of liability in case of a certain nuclear transport accident. Article 4(a) and (b) 1960/2004 PC and Article II.1(b) and (c) 1963/1997 VC, provide explicit rules on transport stipulating that liability, in principle, is typically imposed on the installation operator sending the nuclear substances, including storage incidental thereto, which passes to the receiving operator upon contractual assumption of liability by that operator or, in absence thereof, when that operator takes charge of the shipment. Article 4(d) 1960 PC, Article 4(e) 2004 PC, as well as Article II.2 1963/1997 VC, further contain the option that a Contracting Party may provide by legislation that a carrier, at its request and with the consent of the operator of a nuclear installation situated in its territory, be liable in the place of the operator. In order to prevent contractual liability transfer to operators with the domestically fixed lowest liability cap for transport in order to factoring less expensive insurance premiums into the price of the transport, a new provision, Article 4(c) 2004 PC, stipulates that permits such transfer of transport liability only the other operator has a direct economic interest in the nuclear substances being transported.

In the case of transport to or from operators of non-Contracting Parties, special provisions apply to ensure that an operator to whom the Paris or the Vienna treaty regime (or one of both in case of an existing Joint Protocol link) applies, will remain liable for the entire transport operation as of the moment of loading or unloading of the transport vessel, excluding the liability of the carrier, who would otherwise be liable under common law. In principle, the person liable during transport is the receiving operator of a nuclear facility situated in a Contracting State (Installation State) in respect of nuclear materials sent from a non-Contracting State, after they have been loaded on the means of transport by which they are to be carried from the territory of that non-Contracting State, regardless of any contractual provisions, and vice versa, the sending operator of a Contracting State is liable for materials sent to an operator situated in a non-Contracting State, until unloading of the materials. 
The Joint Protocol links the PC to the VC. Should the operators involved in a transport activity be situated in States that have ratified the Joint Protocol, its rules will be applicable in the determination of the allocation of liability. As such, the Joint Protocol in Article II stipulates that the operator of a nuclear installation situated in a Paris State, shall be liable in accordance with the PC for damage suffered in the territory of a Vienna State, and vice versa, provided both are party to the Joint Protocol. Article III(3) further provides in case of transport accidents, 'the applicable Convention shall be that to which the State is a Party within whose territory the nuclear installation is situated whose operator is liable pursuant to either Article II.1(b) and (c) VC or Article 4(a) and (b) PC. To what extent a Vienna State party to the Joint Protocol should be considered as a Contracting Party or not, in respect of a Paris State that also ratified the Joint Protocol under Article 4(a)(iv)/(b)(iv) PC, and vice versa under Article II.1(b)(iv)/(c)(iv) VC, has been disputed and thus gives room for various interpretations.

If under the nuclear liability regimes no operator is liable, no nuclear liability treaty will be applicable to a possible transport accident, which might trigger the application of other law in respect of transboundary (nuclear) damage. For example, nuclear shipments could take place between two operators not party to any of the nuclear liability treaties, but none the less cause nuclear damage within countries that are party of one of such treaties. The liability allocation will then have to be determined according to other (international) law, even though the domestic law of the victim State might have compensatory funds available for their national victims in the absence of a liable operator under one of the nuclear liability treaties.

Moreover, under Article II.5 VC as well as Article 6(b) PC, the principle of exclusive liability "shall not affect the application of any international convention in the field of transport in force or open for signature, ratification or accession at the date on which this Convention is opened for signature", i.e. any third party liability agreements involving a means of transport or dealing with bills of lading. Therefore, a person suffering damage due to a transport accident may have two rights of action, i.e. one against the operator under the VC or PC and one against the carrier liable under such existing agreement. Although the 1971 Maritime Convention aims to solve this, it theoretically still exists in respect of non-Contracting Parties thereto.

The 1971 Maritime Convention supplements both the Vienna and Paris treaties in relation to maritime transport. Under its liability regime, the operator, and not the carrier, will be exclusively liable for damage resulting from any incident occurring during the maritime carriage of nuclear material. However, it will not apply if either the Paris or Vienna treaty is applicable or national law (provided that it is not less favourable to the victim, covers the damage caused by such nuclear material). As such, Contracting Parties to the 1971 Maritime Convention will have to apply the rules of the Paris of Vienna Convention in order to determine the liability of the operator.

\subsection{Jurisdiction in the case of transport accidents}

The situs of the accident will determine the jurisdiction of the courts as well as applicable law of a particular State (transit, coastal, origin or destination State), the gravity of the accident (transboundary or not), the type of resulting nuclear damages (environmental damage), and possible involvement of injured States not in treaty relation with the State of the liable operator, or those not part of any nuclear liability treaty. These are 
unpredictable elements and can be identified as liability risks for any operator involved in nuclear transport that should be taken into account when agreeing upon a special transport route and transport contract.

Article 13 PC and Article XI VC determine that the jurisdiction and applicable law over actions for compensation, lies in principle, with the courts of the accident State (lex loci delicti), unless the accident occurs in a non-Contracting State during transport, then jurisdiction lies with the courts of the Installation State, i.e. State of the operator liable (lex loci actions). The courts of the Installation State also have jurisdiction in cases where the place of the nuclear incident 'cannot be determined with certainty' or occurs on the high seas.

The 1997 VC and 2004 PC follow the basic jurisdictional rules of the unrevised version, however, in respect of nuclear incidents occurring in the EEZ of a Contracting Party (or, if such zone has not been established, in an area not exceeding the limits of an EEZ were one to be established in the future), jurisdiction will lie only with the courts of that Contracting Party.

As for the applicable substantive law, the competent court will apply the self-executing provisions of the relevant nuclear liability treaty, if these have been made directly applicable within its domestic legal order, or the national legislation specifically enacted in order to implement the applicable treaty. The national law of the court will apply to all matters of a both substantive and procedural nature not specifically governed by the treaties or on aspects where these treaties leave States certain latitude.

Final judgments rendered in the competent court will be recognised by and are enforceable in any of the other Contracting Parties without re-examination of the merits. This applies also to a judgment rendered under the Paris Convention in respect of victims of a Vienna-Joint Protocol State, even if, under the revised Paris Convention, the available compensation might then be conditioned by reciprocity requirements. ${ }^{1}$

\subsection{Transport routes and territorial application}

Whether compensation under a nuclear liability treaty would be available for transport accidents occurring in the course of nuclear materials transports from the sending to the receiving operator situated in another State, depends also upon whether the incident falls within the geographical scope of application.

The territorial application of the $1960 \mathrm{PC}$ is limited to nuclear incidents occurring and nuclear damage suffered in the territory of Contracting Parties, including, as recommended, ${ }^{2}$ the high seas, unless the legislation of the Installation State determines otherwise (Article 2). The geographical scope of application of the Paris Convention would thus vary according to the law of the Installation State.

The geographical applicable scope of the $1963 \mathrm{VC}$ is not explicitly defined. It is clear that it applies whenever the nuclear incident occurs in the territory of a Vienna State, or, if it occurs outside such territory in the course of transport, if the installation of the liable operator is situated within such Vienna State, and if not, the VC will apply if that installation was operated by a Vienna State or under its authority.

The revised Paris and Vienna Conventions extend the geographical application to damage wherever suffered, including the EEZ. Whereas the 1997 VC permits a unilateral exclusion of this extension only in respect of non-Contracting nuclear States (or its maritime zones) that do not afford equivalent reciprocal benefits (Article IA), the 2004 PC 
a priori excludes damage coverage in such case, while excluding a priori also cases where such States lack nuclear legislation based on identical nuclear liability principles as the 2004 PC, unless national legislation provides otherwise (Article 2).

The Joint Protocol expands the geographical scope of the Paris and Vienna Conventions by linking them and establishing a mutual extension of the civil nuclear liability regimes established under both. This means that a nuclear incident at a nuclear facility in a Paris State would be covered on a reciprocal basis under the terms of the Paris Convention in an additional 15 countries. Moreover, the Joint Protocol (Article III) is meant to eliminate conflicts which might otherwise arise, especially in transport cases, from the simultaneous application of the two Conventions: it aims to ensure that either the Paris or the Vienna treaty is applicable to a nuclear incident.

Thus, to determine with some certainty to what extent a potential transport accident would fall within the territorial application of the existing nuclear liability treaties, it is necessary to analyse the domestic laws of the sending, receiving, transit and victim States, situated in the vicinity of planned transport routes and the respective treaty relations among them.

\subsection{Liability limits applicable to transport accidents}

The operator's liability cap will be fixed by the law of the Installation State and will apply wherever the nuclear accident occurs, also in respect of transitional caps fixed temporarily lower than the general liability limit under the revised nuclear liability treaties. Such is stipulated explicitly in Article 7(d) of the 1960/2004 PC, as well as Article V(3) of the 1997 VC. Therefore, in the case of a nuclear transport accident, the operator will not be liable for varying amounts depending on the States transited or where the accident occurred, but will remain to be that amount as determined by the legislation of the Installation State implementing the nuclear liability treaty. As a result, the potential applicable liability limit in the case of accidents occurring in the course of multimodal transboundary transport activities seem less unpredictable, especially once there is certainty about the operator liable.

In respect of the Paris States, this means that even though the treaty maximum liability cap is set at 15 million SDRs, national law generally increased this amount, sometimes even following the OECD Steering Committee recommended maximum of not less than 150 million SDRs. ${ }^{3}$ (e.g. Finland, Belgium, The Netherlands, Sweden). In respect of the Vienna States, most caps are fixed much lower by national law, but never as low as US\$5 million as stipulated in Article V VC.

A special rule exists in respect of transit of nuclear material. Article 7(e) PC provides that a Contracting Party may subject the transit of nuclear substances through its territory to the condition that the maximum amount of liability of the foreign operator concerned be increased, if it considers that such an amount does not adequately cover the risks of a nuclear incident in the course of the transit: provided that the maximum amount thus increased shall not exceed the maximum amount of liability of operators of nuclear installations situated in its territory. Clarity about the liability cap applicable can thus be deduced from an analysis of the various domestic laws of the potential transit States.

Under the 2004 PC, if it will come into force, it will be clear that virtually all Paris operators will provide at least the first 700 million euros of liability coverage, with the rest coming from State contributions. However, lower limits are allowed for the carriage of 
nuclear substances, if fixed not less than 80 million euros. This would thus be the minimum amount available within the PC region for a transport accident involving a liable operator situated in a Paris State. On the other hand, the 1997 VC increased the liability limit to not less than 300 million SDRs, with a minimum operator's liability of 150 million SDRs if the public funds would guarantee the difference. Lower limits can also be established to not less than 5 million SDRs, and provided that the Installation State ensures that public funds provide for the difference (Article V(2) 1997 VC).

In principle, depending upon the applicable treaty and the specific caps as fixed under the domestic law of the Installation State, these will be the amounts available for compensating (transboundary) nuclear damage as a result of a transport accident, if and to the extent it would be covered by one of such nuclear liability treaties.

\subsection{Liability exclusions in respect of transport accidents}

The rules on exoneration of liability are defined in Article 9 1960/2004 PC and Article IV(3) 1963/1997 VC. They stipulate that the operator's liability will be exonerated only where it can prove that the damage was caused by a nuclear incident directly due to an act of armed conflict, hostilities, civil war, insurrection or a grave natural disaster of an exceptional character, unless the law of the Installation State determines otherwise. Acts of terrorism, in principle, do not fall within the exoneration for an 'act of armed conflict' or 'hostilities'. Should a ship or train be subject to a terrorist act, the liable operator will continue to be obliged to provide for compensation up to limit fixed by the law of the Installation State.

As for grave natural disaster of an exceptional character, e.g. hurricanes or tornados causing a nuclear accident in the course of shipment of nuclear material, the operator's liability will still be exonerated under the 1960 PC and 1963 VC, unless the law of the Installation State determines otherwise. However, the revised versions of the Paris and Vienna Conventions, explicitly deleted this exoneration. The operator will therefore remain, just like for terrorist attacks, liable for any resulting nuclear damage caused by such situations of force majeure.

\subsection{Types of nuclear damage covered}

The kind of nuclear damage that would be compensated under the unrevised versions of the Paris Convention (Article 3) and Vienna Convention (Article I(1)(k)(i)) were confined to damage directly linked to that suffered by individuals or their property (other than the nuclear installation itself and any property on the same site), as well as damage that cannot be reasonably separated from nuclear damage, which, in case of transport accidents, arises out of or results from the radioactive properties (or a combination of radioactive properties with toxic, explosive or other hazardous properties) of nuclear fuel or radioactive products or waste coming from, originating in, or sent to a nuclear installation (Article 1(a)(v) PC and Article I(1)(h) VC).

Article I(k)(ii) of the 1963 VC further adds "any other loss or damage so arising or resulting if and to the extent that the law of the competent court so provides". The 1960 PC does not contain this addition. Even so, damage to the general environment per se (water, air, the soil, etc.), still falls outside the scope and can only be compensated if the applicable substantive law so provides. Since it is for the applicable law to determine the 
precise meaning of damage, and the extent to which environmental damage can be compensated under those heads, that wide discretion may lead to uncertainties as to the extent of compensation to be paid in case of a nuclear transport incident.

Under the $1963 \mathrm{VC}$ the operator is, in principle, not liable for nuclear damage to the means of transport unless national law explicitly regulates otherwise (Article IV(5)(b) and IV(6)), whereas under the 1960/2004 PC (Article 7(c)), and the 1997 VC (Article IV(6)) this is optional, leaving it to national law of the State, provided it will not have the effect of reducing the liability of the operator in respect of other damage to a specific amount.

Both the 2004 PC and 1997 VC extended the narrow definition of nuclear damage to explicitly include

(a) economic loss resulting from personal injury or property damage

(b) costs of measures of reinstatement of impaired environment if actually taken or to be taken (unless such impairment is insignificant)

(c) certain loss of income resulting from an (a direct) economic interest in any use or enjoyment of the environment resulting from a significant impairment of the environment

(d) costs of preventive measures and further loss or damage caused by such measures, and only under the $1997 \mathrm{VC}$

(e) any other economic loss. ${ }^{4}$

Consequently, whereas claims for compensation for the enumerated heads of damage must be admitted although the extent of coverage is left to the 'law of the competent court', the admissibility of claims under the latter head (e) is totally dependent upon the provisions of the applicable substantive law. The court will also have to judge upon the remoteness of claims, which is left open by the definition, e.g. whether indirect economic loss sustained are too remote in the chain of causation. ${ }^{5}$ Finally, although (pure) economic loss might be covered, it is, however, necessary that the loss arises out of an emission of ionising radiation. If, for example, a ship with nuclear substances sinks, but there is no emission, economic loss suffered as a result of widespread public fear of contamination will not be covered.

\subsection{Compensation funds under BSC and CSC}

Whereas both the 1963/2004 BSC and the 1997 CSC provide for additional public and joint public funds up to 300 million SDRs, 1.5 billion Euros, and 600 million SDRs, respectively, such supplementary compensation is available only for accidents occurring and damage suffered in the territory of BSC or CSC States (even though including their EEZ), provided an operator of a Contracting Party is liable (i.e. geographically limited). This means that, especially in case of accidents involving transfrontier transport, likely to cause damage in States not party to such treaties, supplementary compensatory funds will not be available, even if they are non-nuclear States.

\section{Conclusion}

As seen from the comparison above between the unrevised and the revised version of the Vienna Convention and the Paris Convention, the 1997 VC and 2004 PC might thus have 
some far reaching consequences for transport activities. In the case of casualties during multimodal and transnational shipments, they would allow victims of Contracting but also non-Contracting non-nuclear States to recover costs of damages resulting from marine contamination or preventive measures (even in the case of the sinking of a ship without the actual release of radiation), and costs of loss of income or other economic damages, give jurisdiction to coastal Contracting States for accidents occurring in their EEZ, as well as set much higher minimum liability limits, also explicitly for transport activities.

With the adoption of the modernised nuclear liability treaties, i.e. the $1997 \mathrm{VC}$, and the 2004 PC and BSC, the lack of transparency of the liability risks involved in transport activities might nevertheless increase, especially as long as not all the Contracting Parties of the original version of the treaties have ratified the modernised ones. Only the CSC, in this respect, is different. The CSC aims to provide a basis for one unified nuclear liability regime attracting the widest possible membership by allowing States to participate no matter which treaty regime they adhere to and States that did not join any such regime but have domestic nuclear liability legislation in place that follows some specified basic nuclear liability principles. As such, it links all States together in one legal regime that aims to apply the main basic nuclear liability principles between and among them. And although a number of aspects and interrelations would still need to be clarified, especially in respect of international transmodal transport activities, the CSC could provide more legal certainty and transparency as to the main liability risks involved.

In addition, the CSC might function as an alternative to the Joint Protocol, which, due to the modernised Paris and Vienna treaties, might become largely redundant. The modernised versions of the Vienna and Paris treaties establish a nuclear liability regime that extends its scope of compensatory rights unconditionally to victims of non-nuclear States. The 1997 VC also applies to damage suffered in nuclear non-Contracting States, regardless of whether they ratified the Joint Protocol, unless that Vienna State used its option to exclude such damage, allowed only if that victim State does not afford 'equivalent reciprocal benefits'. In effect, this means that from the perspective of the 1997 VC, all Paris States whether or not they ratified the Joint Protocol, are covered since they do provide for such reciprocity.

The situation is somewhat different under the 2004 PC, unfortunately. Its geographical application is confined to nuclear damage suffered in non-Contracting States that are non-nuclear States, and in case they are nuclear States if they afford 'equivalent reciprocal benefits' based on identical (i.e. exactly the same) nuclear liability principles, unless national law of the Paris State has broadened its geographical application. So whereas, the revised VC unconditionally includes damage wherever suffered, unless national law imposes a reciprocity requirement in respect of nuclear victim States, the revised PC geographical scope was only extended to damage suffered in all non-nuclear States, whereas in respect of all nuclear victim States the reciprocity and 'identical' condition might, depending upon interpretation, apply unless national law broadens its scope.

In effect, this would make the Joint Protocol redundant under the $1997 \mathrm{VC}$ in the sense that the benefits of the Joint Protocol are extended also to non-Joint Protocol non-Vienna States, as well as under the 2004 PC in the sense that the benefits of the Joint Protocol can now be conditioned in the same manner as to non-Joint Protocol non-Paris States.

Ergo, since as yet there exists no worldwide applicable fixed and unified nuclear liability regime under which potential nuclear damage claims can be settled in a predictable and transparent manner, the CSC, if entering into force, might function as such and prove to be an adequate substitute for the Joint Protocol. 


\section{Notes}

1 See Article XII 1963/1997 Vienna Convention and Article 13 1960/2004 Paris Convention in conjunction with Article IV of the Joint Protocol and Articles 2(a) and 7(g) of the 2004 Paris Convention.

2 The Paris Convention Steering Committee recommended that parties extend the PC's geographical application by national legislation (a) to damage suffered in a Contracting State or on the high seas on board a ship registered in the territory of a Contracting State (even if the nuclear incident causing the damage has occurred in a non-Contracting State) and that (b) to damage suffered and incidents occurring on the high seas (i.e. res communis). OECD Steering Committee Recommendations of 25.4.1968 [NE/M(68)1] and of 22.4.1971 NE/M(71)1], respectively. The latter would, in practice, apply only to damage occurring in the course of carriage, since it is only in this case that the operator of a Contracting State could be held liable under the PC for an incident occurring in a non-Contracting State. However, some national laws, e.g. in France, do not follow this recommendation.

3 Recommendation of the OECD Steering Committee of 20.4.1990 [NE/M(90)1], Paris Convention: Decisions, Recommendations, Interpretations (Paris: OECD/NEA, 1990) at 13.

4 The residual category of economic loss is not covered by the new definition of 'nuclear damage' adopted in the 2004 PC, a definition which is otherwise almost identical to that found in the 1997 VC. Apparently, as is stated in the Explanatory Report attached to the 2004 PC, 'the Paris Convention States were simply not convinced that this head of damage was not already covered by other heads of damage included in the definition' (paragraph 12).

5 Whereas Article I.1(k)(v) of the $1997 \mathrm{VC}$ refers to "loss of income deriving from an economic interest in any use or enjoyment of the environment", the corresponding provision in the 2004 PC, Article 1(a)(vii)(5) leaves less discretion to the competent court, since it covers loss of income deriving from a 'direct' economic interest in the use or enjoyment of the environment. 